\title{
Synthesis of water soluble axially disubstituted silicon (IV) phthalocyanines with alkyne \& azide functionality
}

\author{
Yuriy Bandera ${ }^{b}$, Mary K. Burdette ${ }^{a, b}$, Jamie A. Shetzline ${ }^{c, b}$, Ragini Jenkins ${ }^{a, b}$, \\ Stephen E. Creager ${ }^{c, b}$, and Stephen H. Foulger ${ }^{a, b *}$ \\ ${ }^{a}$ Department of Materials Science and Engineering \\ ${ }^{b}$ Center for Optical Materials Science and Engineering Technologies \\ ${ }^{c}$ Department of Chemistry \\ Clemson University, Clemson, SC 29634-0971, USA
}

*To whom correspondence should be addressed; e-mail: foulger@clemson.edu.

September 24, 2015

KEWORDS: phthalocyanine, silicon, click chemistry, water soluble, synthesis, azide, alkyne, polyethylene glycol

\begin{abstract}
Phthalocyanines (Pcs) are a class of photosensitizers (PSs) with a strong tendency to aggregate in aqueous solutions, which has a negative influence on their photosensitizing ability for photodynamic therapy. Four new axially disubstituted, non-aggregated silicon phthalocyanines (SiPcs), containing azide or alkyne functional groups have been synthesized and characterized. The method of synthesis is based on the reaction of silicon phthalocyanine dichloride with variable length poly(ethylene glycol) (PEG) chains in the presence of $\mathrm{NaH}$. All synthesized dyes are highly soluble in alcohols, $\mathrm{THF}, \mathrm{CH}_{2} \mathrm{Cl}_{2}$, acetone, DMF and other common polar organic solvents, with the PEGylated silicon phthalocyanines (SiPcs) also being soluble in water. Photophysical and electrochemical properties of the dyes have been investigated. The presence of alkyne or azide groups in the phthalocyanine dyes, coupled with their high aqueous solubility, make these compounds useful as building blocks in copper catalyzed Huigsen azide-alkyne cycloaddition reactions (i.e. click chemistry).
\end{abstract}

C 2015. This manuscript version is made available under the Elsevier user license http://www.elsevier.com/open-access/userlicense/1.0/ 


\section{Introduction}

Phthalocyanines (Pcs) and their metal complexes have intense absorption in the far red region, low dark toxicity, good chemical stability, and a propensity to generate reactive oxygen species when excited[1,2]. These properties make Pcs interesting for the development of new photosensitizers (PS) for photodynamic therapy (PDT)[3]. Currently, PDT is broadly used in medicine for the treatment of various conditions, including a variety of cancers[4-6]. Pcs used for PDT include zinc phthalocyanines (ZnPcs) [7, 8], aluminum phthalocyanines (AlPcs) $[6,9,10]$, and silicon phthalocyanines (SiPcs)[11-14]. However, most of these compounds exhibit high levels of aggregation in common organic solvents and aqueous media. Silicon Pcs have a relatively reduced tendency to aggregate in solution, which accounts for their high solubility and more pronounced fluorescence lifetimes[15, 16]. Despite the large amount of non-aggregated, axially substituted SiPc derivatives presented in the past few years[12-14, 17-21], these systems tend to exhibit broad emission characteristics and are not amenable for use in more complex heterostructures due to their limited chemical attachment sites. The main goal of this research was the synthesis of new, versatile, non-aggregated axially disubstituted silicon phthalocyanine ( $\mathrm{SiPc}$ ) complexes, which can be used in future investigations either as small molecules or as a part of a larger heterostructure. These systems were modified with substituents containing azide or alkyne functional groups making them amenable for use in reactions which exploit the copper catalyzed Huigsen azide-alkyne cycloaddition (i.e. "click chemistry")[22]. Current efforts have been presented of Pcs modified for use in click chemistry with azide groups[23-25] or alkyne groups[26-31], but all of these compounds have the substituents in peripheral positions, with only one SiPc complex having axially attached substituents containing an alkyne[32]. The main challenge of peripherally substituted Pcs is their

high propensity to aggregate and their limited synthetic approach[33, 34, 11]. Axially substituted Pcs are much less likely to aggregate due to the interuption of the $\pi$-system by the non-planar substituents issuing from the center metal atom[35].

For the purpose of increasing the solubility of SiPc complexes in water and other common organic solvents, we have synthesized a new series of axially disubstituted, non-aggregated SiPcs, containing either alkyne or azide functionality. These new symmetrical SiPc complexes can be easily modified by click reactions with 
other appropriate small molecules, nano- or micro-particles, polymers, and proteins. This feature makes them valuable for future investigations because the nature of the substituents has a strong influence on the optical and physical parameters of phthalocyanines. Photophysical and electrochemical properties of the synthesized compounds have been studied.

\section{Experimental}

\subsection{Materials and equipment}

Silicon phthalocyanine dichloride $\left(\mathrm{SiPcCl}_{2}\right)$, triethylene glycol, and polyethylene glycol 600 (PEG 600) were purchased from Sigma-Aldrich. Other reagents were purchased from Alfa Aesar. All commercial reagents were used without further purification. All solvents were dried according to standard methods. Triethylene

glycol and PEG 600 were dried in THF solutions over A4 molecular sieves. ${ }^{1} \mathrm{H}$ and ${ }^{13} \mathrm{C}$ NMR spectra were recorded on a JEOL ECX300 spectrometer $(300 \mathrm{MHz}$ for proton and $76 \mathrm{MHz}$ for carbon). Chemical shifts for protons are reported in parts per million downfield from tetramethylsilane and are referenced to residual protium in the NMR solvent (CDCl3: $\delta 7.26 \mathrm{ppm}$, DMSO-d6: $\delta 2.50 \mathrm{ppm}$ ). Electrospray (ESI) mass spectra were obtained using Finnigan LCQ spectrometer and HP 1100 (HPLC). Absorption spectra were taken using a Perkin-Elmer Lambda 950 UV/VIS/NIR spectrophotometer. Photoluminescence (PL) spectra were collected using a Photon Technology International QuantaMaster 60 NIR with a PMT spectrofluorometer and a Thermo Oriel xenon arc lamp (Thermo Oriel 66902) mated with a Thermo Oriel Cornerstone 7400 1/8 m monochromator (Thermo Oriel 7400). Fourier transform infrared (FTIR) spectra were obtained with a Nicolet 6700 by Thermo Scientific FT-IR spectrometer and all spectra were measured with FTIR-ATR with a diamond head.

Cyclic voltammetery was utilized to determine the electrochemical characteristics of the SiPc compounds. A three electrode system was utilized with a platinum disk working electrode, a platinum coiled wire counter electrode, and a $\mathrm{Ag} / \mathrm{AgCl}$ reference electrode with an outer junction to prevent water contamination of the solutions. The Pt disk was polished with $5 \mu \mathrm{m}$ alumina between runs. $0.1 \mathrm{M} \mathrm{TEABF}_{4}$ in $\mathrm{ACN}_{\text {was }}$ used as the electrolyte. For each test, $2 \mathrm{~mL}$ of electrolyte was added to a vial and bubbled with $\mathrm{N}_{2}$. A background 
scan was collected. After the background had been collected, $200 \mu \mathrm{L}$ of $11 \mathrm{mM}$ SiPc complexes in ACN were added to the solution (concentration in solution was $1 \mathrm{mM}$ ), and purged with $\mathrm{N}_{2}$. Three sweeps were performed from $0 \mathrm{~V}$ to $1.6 \mathrm{~V}$ and then to $-1.4 \mathrm{~V}$ at $100 \mathrm{mV} / \mathrm{s}$. After the $\mathrm{CV}$ of the $\mathrm{SiPc}$ derivatives were completed, $10 \mu \mathrm{L}$ of $25 \mathrm{mM} \mathrm{FC}$ in $0.1 \mathrm{M} \mathrm{TBABF}_{4}$ was added to the solution, and the scans were repeated in the same manner after purging with $\mathrm{N}_{2}$. The addition of ferrocene resulted in no shifting or interaction with the SiPcs. FC had a $\mathrm{E}_{(1 / 2)}$ of $0.412 \mathrm{~V}$, and $\Delta \mathrm{E}_{p}$ of $78 \mathrm{mV}$.

\subsection{Synthesis and characterization data}

\subsubsection{Synthesis of compound 1a}

Compound 1a was synthesized according to literature[36]. Sodium hydride (0.32 g, $13.32 \mathrm{mmol})$ was added to the solution of triethylene glycol $(2 \mathrm{~g}, 13.32 \mathrm{mmol})$ in tetrahydrofuran $(30 \mathrm{ml})$. The obtained mixture was stirred at room temperature for $30 \mathrm{~min}$ then propargyl bromide solution (80\%) in toluene $(2 \mathrm{~g}, 13.45 \mathrm{mmol})$ was added. The mixture was stirred for $6 \mathrm{~h}$ at room temperature and filtered. The filtrate was evaporated; the residue was extracted with dichloromethane and washed with water. The organic solution was dried with $\mathrm{Na}_{2} \mathrm{SO}_{4}$, filtered, and evaporated under reduced pressure to yield a brown oil. The crude product was purified by flash column chromatography on silica. The first eluent was dichloromethane, which serves to remove a majority of the impurities. A second eluent, acetone, was used to collect the product. Yield: 1.63 g (65\%), pale yellow oil. ${ }^{1} \mathrm{H}$ NMR $\left(\mathrm{CDCl}_{3}\right) \delta 2.43(\mathrm{t}, 1 \mathrm{H}, J=2.4 \mathrm{~Hz}, \mathrm{CCH}), 3.61\left(\mathrm{~m}, 2 \mathrm{H}, \mathrm{OCH}_{2}\right), 3.67-3.74$ $\left(\mathrm{m}, 10 \mathrm{H}, \mathrm{OCH}_{2}\right), 4.21\left(\mathrm{~d}, 2 \mathrm{H}, J=2.4 \mathrm{~Hz}, \mathrm{CH}_{2} \mathrm{CC}\right)$.

\subsubsection{Synthesis of compound $1 \mathrm{~b}$}

Compound $\mathbf{1 b}$ was synthesized according to the above procedure. The crude product was washed with hexanes twice, decanted, dried, and used in the next step without further purification. Yield: 83\%, clear oil. ${ }^{1} \mathrm{H} \mathrm{NMR}\left(\mathrm{CDCl}_{3}\right) \delta 1.83(\mathrm{~s}, 1 \mathrm{H}, \mathrm{OH}), 2.43(\mathrm{t}, 1 \mathrm{H}, J=2.4 \mathrm{~Hz}, \mathrm{CCH}), 3.60-3.71\left(\mathrm{~m}, 56 \mathrm{H}, \mathrm{OCH}_{2}\right), 4.20(\mathrm{~d}, 2 \mathrm{H}$, $\left.J=2.4 \mathrm{~Hz}, \mathrm{CH}_{2} \mathrm{CC}\right)$. 


\subsubsection{Synthesis of compound $2 \mathrm{a}$}

Methanesulfonyl chloride $(3.2 \mathrm{~g}, 27.94 \mathrm{mmol})$ was added to the solution of triethylene glycol $(4 \mathrm{~g}, 26.64$ $\mathrm{mmol})$ in dichloromethane $(50 \mathrm{ml})$. The reaction was cooled with ice. Triethylamine $(2.97 \mathrm{~g}, 29.3 \mathrm{mmol})$ was added dropwise to the stirred solution. The ice bath was removed, and the obtained mixture was stirred at room temperature for $6 \mathrm{~h}$. The reaction mixture was then washed with water twice. The organic solution was dried with $\mathrm{Na}_{2} \mathrm{SO}_{4}$, filtered, and evaporated under reduced pressure. The obtained product contains approximately $10 \%$ of bis-methylsulfonylated triethylene glycol and was used in the next step without additional purification. Yield: $3.6 \mathrm{~g}(59 \%)$, clear oil. ${ }^{1} \mathrm{H} \mathrm{NMR}\left(\mathrm{CDCl}_{3}\right) \delta 3.07(\mathrm{~s}, 3 \mathrm{H}), 3.61(\mathrm{~m}, 2 \mathrm{H}$, $\left.\mathrm{CH}_{2} \mathrm{OH}\right), 3.67(\mathrm{~m}, 4 \mathrm{H}), 3.76(\mathrm{~m}, 4 \mathrm{H}), 4.37\left(\mathrm{~m}, 2 \mathrm{H}, \mathrm{CH}_{2} \mathrm{OSO}_{2}\right)$.

\subsubsection{Synthesis of compound $2 b$}

Compound $\mathbf{2} \mathbf{b}$ was synthesized according to the above procedure and was used in the next step without additional purification. Yield: 87\%, clear oil. ${ }^{1} \mathrm{H}$ NMR $\left(\mathrm{CDCl}_{3}\right) \delta 3.07(\mathrm{~s}, 3 \mathrm{H}), 3.58-372(\mathrm{~m}, 40 \mathrm{H}), 3.75(\mathrm{~m}$, $2 \mathrm{H}), 4.37\left(\mathrm{~m}, 2 \mathrm{H}, \mathrm{CH}_{2} \mathrm{OSO}_{2}\right)$.

\subsubsection{Synthesis of compound 3a}

Compound 2a (3.6 g, $15.77 \mathrm{mmol})$ was dissolved in acetonitrile $(20 \mathrm{ml})$, and sodium azide (2.56 g, 39.38 mmol) was added to the solution. The obtained mixture was stirred and refluxed for $16 \mathrm{~h}$. After cooling, the mixture was extracted with dichloromethane and was washed with water. The organic solution was dried with $\mathrm{Na}_{2} \mathrm{SO}_{4}$, filtered, and evaporated under reduced pressure. The obtained product contains about $10 \%$ of bis-azido-derivative, but it was used in the next step without additional purification. Yield: $2.47 \mathrm{~g}(89 \%)$, clear oil. ${ }^{1} \mathrm{H}$ NMR $\left(\mathrm{CDCl}_{3}\right) \delta 3.38\left(\mathrm{t}, 2 \mathrm{H}, J=4.8 \mathrm{~Hz}, \mathrm{CH}_{2} \mathrm{~N}_{3}\right), 3.59-3.79(\mathrm{~m}, 10 \mathrm{H})$.

\subsubsection{Synthesis of compound $4 \mathrm{a}$}

Silicon phthalocyanine dichloride $(0.2 \mathrm{~g}, 0.33 \mathrm{mmol})$ was mixed with dry toluene $(4 \mathrm{ml})$, and the solution of compound 3a $(0.17 \mathrm{~g}, 0.97 \mathrm{mmol})$ in toluene $(2 \mathrm{ml})$ was added to the reaction mixture. The mixture was stirred under a nitrogen atmosphere for 5 minutes and sodium hydride $(0.023 \mathrm{~g}, 0.96 \mathrm{mmol})$ was added. The 
mixture was refluxed for $20 \mathrm{~h}$. After cooling, the solution was extracted with ethyl acetate and was washed with water. The organic solution was dried with $\mathrm{Na}_{2} \mathrm{SO}_{4}$, filtered, and evaporated under reduced pressure. The residue was washed with hexanes. The organic solution was decanted away from the insoluble product, and the product was purified by flash column chromatography on silica with an eluent of a solution of dichloromethane:acetone $(10: 1), \mathrm{R}_{f}=0.3$. The dry product was dissolved in a minimum of dichloromethane and was added dropwise to hexane solution. The precipitates from this solution were filtered, collected, and dried. Yield: $0.13 \mathrm{~g}(45 \%)$, blue crystals, mp $169-170{ }^{\circ} \mathrm{C}$ with destruction. ${ }^{1} \mathrm{H}$ NMR $\left(\mathrm{CDCl}_{3}\right) \delta-1.91(\mathrm{t}$, $\left.4 \mathrm{H}, J=5.5 \mathrm{~Hz}, \mathrm{CH}_{2} \mathrm{OSi}\right), 0.42\left(\mathrm{t}, 4 \mathrm{H}, J=5.5 \mathrm{~Hz}, \mathrm{CH}_{2}\right), 1.66\left(\mathrm{t}, 4 \mathrm{H}, J=4.8 \mathrm{~Hz}, \mathrm{CH}_{2}\right), 2.45(\mathrm{t}, 4 \mathrm{H}, J=4.8 \mathrm{~Hz}$, $\left.\mathrm{CH}_{2}\right), 2.92\left(\mathrm{~m}, 8 \mathrm{H}, \mathrm{CH}_{2} \mathrm{CH}_{2} \mathrm{~N}_{3}\right), 8.34(\mathrm{dd}, 8 \mathrm{H}, J=3.1 \mathrm{~Hz}, \mathrm{ArH}), 9.63(\mathrm{dd}, 8 \mathrm{H}, J=3.1 \mathrm{~Hz}, \mathrm{ArH}) .{ }^{13} \mathrm{C} \mathrm{NMR}$ $\left(\mathrm{CDCl}_{3}\right) \delta 50.36,54.92,68.83,69.24,69.54,69.58,123.78,131.03,136.13,149.38(\mathrm{CN}) . \mathrm{ESI}^{+}$Mass $(\mathrm{m} / \mathrm{z})$ : calculated for $\mathrm{C}_{44} \mathrm{H}_{40} \mathrm{~N}_{14} \mathrm{O}_{6} \mathrm{Si}[\mathrm{M}+\mathrm{Na}]^{+}$911.29, found 911.0

\subsubsection{Synthesis of compound $4 \mathrm{~b}$}

Compound $\mathbf{4} \mathbf{b}$ was synthesized according to the procedure of $\mathbf{4 a}$ with the substitution of compound $\mathbf{3 b}$ for compound 3a. Compound $\mathbf{4 b}$ was purified by flash column chromatography on silica with an eluent of a solution of dichloromethane:methanol (10:1). $\mathrm{R}_{f}=0.4$. Yield: $66 \%$, dark blue oil. ${ }^{1} \mathrm{H}$ NMR $\left(\mathrm{CDCl}_{3}\right) \delta-1.92$ (t, $\left.4 \mathrm{H}, J=5.5 \mathrm{~Hz}, \mathrm{CH}_{2} \mathrm{OSi}\right), 0.37\left(\mathrm{t}, 4 \mathrm{H}, J=5.5 \mathrm{~Hz}, \mathrm{CH}_{2}\right), 1.66\left(\mathrm{t}, 4 \mathrm{H}, J=4.8 \mathrm{~Hz}, \mathrm{CH}_{2}\right), 2.44(\mathrm{t}, 4 \mathrm{H}, J=5.2$ $\left.\mathrm{Hz}, \mathrm{CH}_{2}\right), 2.96\left(\mathrm{t}, 4 \mathrm{H}, J=4.8 \mathrm{~Hz}, \mathrm{CH}_{2}\right), 3.21\left(\mathrm{t}, 4 \mathrm{H}, J=5.2 \mathrm{~Hz}, \mathrm{CH}_{2}\right), 3.37\left(\mathrm{~m}, 8 \mathrm{H}, \mathrm{CH}_{2}\right), 3.44\left(\mathrm{~m}, 4 \mathrm{H}, \mathrm{CH}_{2}\right)$, 3.51-3.69 (m, 70H, $\left.\mathrm{CH}_{2}\right), 8.33(\mathrm{dd}, 8 \mathrm{H}, J=3.1 \mathrm{~Hz}, \mathrm{ArH}), 9.62(\mathrm{dd}, 8 \mathrm{H}, J=3.1 \mathrm{~Hz}, \mathrm{ArH}) .{ }^{13} \mathrm{C} \mathrm{NMR}\left(\mathrm{CDCl}_{3}\right)$ $\delta 50.79,54.80,68.68,69.46,69.90,70.16,70.20,70.39,70.48,70.54,70.69-70.81(\mathrm{~m}), 123.77,130.98,136.10$, $149.34(\mathrm{CN})$. ESI ${ }^{+}$Mass (m/z): calculated for compound 4b avg. $\mathrm{C}_{86} \mathrm{H}_{12} 4 \mathrm{~N}_{14} \mathrm{O}_{26} \mathrm{Si}[\mathrm{M}+\mathrm{H}]^{+} 1797.87$, found multiple peaks starting from 1963 (See Supplementary Information).

\subsubsection{Synthesis of compound 5a}

Silicon phthalocyanine dichloride $(0.2 \mathrm{~g}, 0.33 \mathrm{mmol})$ was mixed with dry toluene $(4 \mathrm{ml})$ and the solution of compound 1a $(0.19 \mathrm{~g}, 1.0 \mathrm{mmol})$ in toluene $(2 \mathrm{ml})$ was added to the reaction vessel. The obtained mixture was stirred under a nitrogen atmosphere for 5 minutes and sodium hydride $(0.023 \mathrm{~g}, 0.96 \mathrm{mmol})$ was added. 
The mixture was stirred and refluxed for $20 \mathrm{~h}$. After cooling, the mixture was extracted with ethyl acetate and was washed with water. The organic solution was collected, dried with $\mathrm{Na}_{2} \mathrm{SO}_{4}$, filtered, and evaporated under reduced pressure. Compound 5a was purified by flash column chromatography on silica with an eluent of a 3:1 dichloromethane:acetone solution, $\mathrm{R}_{f}=0.2$. The dry product was dissolved in a minimum of dichloromethane and added dropwise to hexanes solution. The precipitates from this solution were filtered, collected, and dried. Yield: $53 \%$, blue crystals, mp 172-173 ${ }^{\circ} \mathrm{C} .{ }^{1} \mathrm{H}$ NMR $\left(\mathrm{CDCl}_{3}\right) \delta-1.90(\mathrm{t}, 4 \mathrm{H}, J=5.5$ $\mathrm{Hz}, \mathrm{CH}_{2} \mathrm{OSi}$ ), 0.40 (t, 4H,J=5.5 Hz, $\mathrm{CH}_{2}$ ), 1.67 (t, 4H, J=4.8 Hz, $\mathrm{CH}_{2}$ ), 2.34 (t, 2H, J=2.4 Hz, CCH), $2.46\left(\mathrm{t}, 4 \mathrm{H}, J=4.8 \mathrm{~Hz}, \mathrm{CH}_{2}\right), 2.98\left(\mathrm{t}, 4 \mathrm{H}, J=4.8 \mathrm{~Hz}, \mathrm{CH}_{2}\right), 3.29\left(\mathrm{t}, 4 \mathrm{H}, J=4.8 \mathrm{~Hz}, \mathrm{CH}_{2}\right), 3.95(\mathrm{~d}, 4 \mathrm{H}, J=2.4$ $\left.\mathrm{Hz}, \mathrm{CH}_{2} \mathrm{CC}\right), 8.34(\mathrm{dd}, 8 \mathrm{H}, J=3.1 \mathrm{~Hz}, \mathrm{ArH}), 9.63(\mathrm{dd}, 8 \mathrm{H}, J=3.1 \mathrm{~Hz}, \mathrm{ArH}) .{ }^{13} \mathrm{C} \mathrm{NMR}\left(\mathrm{CDCl}_{3}\right) \delta 54.85$, $58.29,68.72,68.84,69.48,69.53,69.75,74.47,79.76,123.79,131.0,136.13,149.37(\mathrm{CN}) . \mathrm{ESI}^{+}$Mass $(\mathrm{m} / \mathrm{z})$ : calculated for $\mathrm{C}_{50} \mathrm{H}_{46} \mathrm{~N}_{8} \mathrm{O}_{8} \mathrm{Si}[\mathrm{M}+\mathrm{Na}]^{+}$937.31, found 937.13.

\subsubsection{Synthesis of compound $5 b$}

Compound $\mathbf{5} \mathbf{b}$ was synthesized according to the procedure of $\mathbf{5} \mathbf{a}$ with the substitution of compound $\mathbf{1} \mathbf{b}$ for compound 1a. Compound $\mathbf{5 b}$ was purified by flash column chromatography on silica. Two eluents were employed. The first eluent was ethyl acetate and was used to remove the majority of impurities. The second eluent was a 3:1 solution of dichloromethane:methanol and was used to remove the remaining impurities and to wash the product from the silica. $\mathrm{R}_{f}=0.2$. Yield: $64 \%$, dark blue oil. ${ }^{1} \mathrm{H} \mathrm{NMR}\left(\mathrm{CDCl}_{3}\right) \delta-1.92(\mathrm{t}, 4 \mathrm{H}$, $\left.J=5.5 \mathrm{~Hz}, \mathrm{CH}_{2} \mathrm{OSi}\right), 0.37\left(\mathrm{t}, 4 \mathrm{H}, J=5.5 \mathrm{~Hz}, \mathrm{CH}_{2}\right), 1.64\left(\mathrm{t}, 4 \mathrm{H}, J=4.8 \mathrm{~Hz}, \mathrm{CH}_{2}\right), 2.44(\mathrm{~m}, 6 \mathrm{H}, J=4.8 \mathrm{~Hz}$, $\mathrm{CH}_{2}$ and $\left.\mathrm{CCH}\right), 2.96\left(\mathrm{~m}, 4 \mathrm{H}, \mathrm{CH}_{2}\right), 3.20\left(\mathrm{~m}, 4 \mathrm{H}, \mathrm{CH}_{2}\right), 3.36\left(\mathrm{~m}, 4 \mathrm{H}, \mathrm{CH}_{2}\right), 3.44\left(\mathrm{~m}, 4 \mathrm{H}, \mathrm{CH}_{2}\right), 3.49-3.71$ $\left(\mathrm{m}, 80 \mathrm{H}, \mathrm{CH}_{2}\right), 4.21\left(\mathrm{~d}, 4 \mathrm{H}, J=2.4 \mathrm{~Hz}, \mathrm{CH}_{2} \mathrm{CC}\right), 8.34(\mathrm{dd}, 8 \mathrm{H}, J=2.8 \mathrm{~Hz}, \mathrm{ArH}), 9.62(\mathrm{dd}, 8 \mathrm{H}, J=2.8 \mathrm{~Hz}$,

ArH). ${ }^{13} \mathrm{C} \mathrm{NMR}\left(\mathrm{CDCl}_{3}\right) \delta 54.80,58.53,68.68,69.21,69.43,69.46,69.89,70.20,70.38,70.47,70.52,70.68$ (m), 74.69, 79.77, 123.77, 130.99, 136.10, 149.35(CN). ESI ${ }^{+}$Mass (m/z): calculated for compound $5 \mathbf{b}$ avg. $(\mathrm{n}=10-11) \mathrm{C}_{90} \mathrm{H}_{126} \mathrm{~N}_{8} \mathrm{O}_{28} \mathrm{Si}[\mathrm{M}+\mathrm{K}]^{+}$1817.83, found 1818.40. 


\subsection{Results \& Discussion}

\subsubsection{Synthesis and characterization}

The new axially disubstituted SiPc complexes $\mathbf{4 a}, \mathbf{b}$ and $\mathbf{5 a}$, b were synthesized starting from commercially available silicon phthalocyanine dichloride $\left(\mathrm{SiCl}_{2} \mathrm{Pc}\right)$, as presented in Figure $2 . \mathrm{SiCl}_{2} \mathrm{Pc}$ reacts with modified triethylene glycols of variable molecular weights in the presence of $\mathrm{NaH}$ in a toluene solution. The reaction requires high temperatures and leads to the nucleophilic substitution of two chlorine atoms with good yields of the final products after purification. For this method, the nucleophilic substituent ligands can vary.[21] As key intermediates, we used either triethylene glycol derivatives (1a or $\mathbf{3 a}$ ) with azide or alkyne terminal groups and the corresponding PEG 600 derivatives (1) or $\mathbf{3 b}$ ). The synthetic pathway to compounds $\mathbf{1 a}, \mathbf{b}$ and $\mathbf{3 a}, \mathbf{b}$ is described in Figure 1.

Compounds 1a, b were synthesized in one step from triethylene glycol or PEG600 by the nucleophilic substitution of one hydrogen in the hydroxyl group to the propargyl group. The reaction was performed in THF in the presence of $\mathrm{NaH}$ and propargyl bromide. Compounds $\mathbf{3 a}, \mathbf{b}$ were synthesized in two steps from the same starting material used for the synthesis of $\mathbf{1 a}, \mathbf{b}$. The first intermediate is mesylates $(\mathbf{2} \mathbf{a}, \mathbf{b})$. The reaction of triethylene glycol with a small excess of methanesulfonyl chloride in dichloromethane yields $\mathbf{2 a}$. The obtained compound $\mathbf{2 a}$ contains a small amount of bismesylated derivative, but it can be used in the next step without additional purification because disubstituted impurities will not react with $\mathrm{SiPcCl}_{2}$ in the final stage of the synthesis of compound $\mathbf{5 a}$. Compound $\mathbf{2} \mathbf{b}$ was synthesized similarly to $\mathbf{2 a}$. Treatment of $\mathbf{2 a}, \mathbf{b}$ with sodium azide in refluxed acetonitrile yields mono-azide derivatives of triethylene glycol and PEG $600(\mathbf{3 a}, \mathbf{b})$ with high yields.

All synthesized axially disubstituted SiPcs were verified by ${ }^{1} \mathrm{H},{ }^{13} \mathrm{C}$ NMR, and ESI Mass analyses. The presence of azide groups in PEGylated SiPc (4b) was also confirmed by FTIR analysis. The azide groups

on $\mathbf{4 b}$ have a strong absorption at $2098 \mathrm{~cm}^{-1}$ (see Supplementary Information). The ${ }^{1} \mathrm{H}$ NMR spectra of the final products $\mathbf{4 a}, \mathbf{b}$ and $\mathbf{5 a}, \mathbf{b}$ shows the shielding of the axial substituent protons by the electron cloud of the SiPc ring. Well-separated, upfield shifted triplets, starting from -1.92 ppm, show methylene protons (cf. Figure 4). 
The closer the atoms of the axial substituents are to the point of attachment to the SiPc ring, the larger the upfield shift of the methylene groups in the proton spectrum. The obtained NMR spectrum corresponds to previous reports for similar compounds[11, 13, 21]. Alkyne protons in modified triethylene glycols $\mathbf{1 a}, \mathbf{b}$ and PEGylated SiPcs 5 b show a triplet at 2.43 ppm, while, for the shorter analog $\mathbf{5 a}$, the signal is shifted to $2.34 \mathrm{ppm}$. The same behavior is observed for $\mathrm{CH}_{2}$ protons attached to the azide group; the triplet from $3.37 \mathrm{ppm}(\mathbf{3 a}, \mathbf{b}$ and $\mathbf{4 b})$ is shifted to $2.93 \mathrm{ppm}$ in compound $\mathbf{4 a}$. Aromatic protons in the final SiPcs show two, well-separated downfield shifted multiplets.

Figure 3 shows the ESI mass analysis of $\mathrm{SiPc} \mathbf{5 b}$. Multiple peaks are separated by 44 mass units $\left[\mathrm{OCH}_{2} \mathrm{CH}_{2}\right]^{+}$starting from molecular ion $\mathrm{M}^{+}$. Compound $\mathbf{4 b}$ shows similar results (see Supplementary Information).

SiPcs $\mathbf{4 a}, \mathbf{b}$ and $\mathbf{5 a}, \mathbf{b}$ are soluble in alcohols, acetone, dichloromethane and other common, polar, organic solvents excluding diethyl ether. PEGylated SiPcs $\mathbf{4} \mathbf{b}$ and $\mathbf{5} \mathbf{b}$ have good solubility in water. Crude products were easily purified by flash column chromatography on silica.

\subsubsection{Photophysical properties}

The UV-Vis absorption spectra of $\mathbf{4} \mathbf{a}, \mathbf{b}$ and $\mathbf{5 a}, \mathbf{b}$, in methanol, are displayed in Figure 5. The relevant spectroscopic parameters are summarized in Table 1. All synthesized SiPcs showed a sharp, intense, welldefined absorption peak (Q-band) at 671-676 nm along with two vibrational bands at 604 and $645 \mathrm{~nm}$, and a B-band at 330-360 nm, depending on the particular SiPc. These absorption bands are indicative of a non-aggregated SiPc for all newly synthesized SiPcs. The same results were obtained in THF and DMSO; all compounds did not show any aggregation. The maximum fluorescence emission for compounds $\mathbf{4 a}, \mathbf{b}$ and $\mathbf{5 a}, \mathbf{b}$, in methanol, occurred at $680 \mathrm{~nm}$ when excited at $630 \mathrm{~nm}$..

The absorption spectra for SiPcs $\mathbf{4} \mathbf{b}$ and $\mathbf{5 b}$, in water, is provided in Figure 6. PEGylated SiPc $\mathbf{4} \mathbf{b}$, was dissolved in water at a concentration of $5 \mu \mathrm{g} / \mathrm{mL}$, and it showed a strong absorption peak at $676 \mathrm{~nm}$, which is characteristic of non-aggregated $\mathrm{SiPc}$. The water solubility of $\mathbf{4 b}$ is $3 \mathrm{mg} / \mathrm{mL}$. Compound $\mathbf{5} \mathbf{b}$ shows a strong Q band in water at $720 \mathrm{~nm}$, which suggests that the dye molecules are self-associating. The water

solubility of $\mathbf{5 b}$ is $0.2 \mathrm{mg} / \mathrm{mL}$. The aggregation behavior of $\mathbf{5} \mathbf{b}$ can be explained by the presence of lipophilic 
alkyne groups at the end of the PEG chains; it decreases solubility in water and makes aggregation easier. Increasing the length of the PEG chains in SiPcs could allow for new dyes with even greater solubility in water. The emission spectra of both $\mathbf{4} \mathbf{b}$ and $\mathbf{5} \mathbf{b}$ show J-aggregates at $761 \mathrm{~nm}$ and $757 \mathrm{~nm}$, respectively. This red-shifted peak does suggest that there are aggregates of $\mathbf{4 b}$ and $\mathbf{5 b}$ forming, but these peaks are much less pronounced than in the spectra of similar SiPcs, which indicates that there is minimal aggregation in this system. It should also be noted that $\mathbf{4 b}$ has just a slight J-aggregate peak, with $\mathbf{5 b}$ having quite a large $\mathbf{J}$ aggregate peak, which agrees with the absorption spectra obtained for both of these molecules. J-aggregates occur when the dye has self associated with itself and are characterized by a longer emission wavelength than the "isolated" dye molecule. J-aggregates are undesirable in this case because they represent a path of non-radiative energy transfer, which will decrease singlet oxygen generation when the dye is utilized in $\operatorname{PDT}[37]$.

The molar extinction coefficient $(\varepsilon)$ and fluorescence quantum yield $\left(\phi_{F}\right)$ for all synthesized phthalocyanines were calculated. The data is summarized in Table $2 . \mathrm{ZnPc}\left(\phi_{F}=0.3\right)$ and $1 \%$ pyridine in toluene solution as a standard was used for fluorescence quantum yield calculations.[38] All silicon phthalocyanine derivates had a much greater fluorescence quantum yield than the standard $\mathrm{ZnPc}$, which indicates that the $\mathrm{SiPc}$ derivatives have more electrons that fluoresce upon excitation and relaxation. This is beneficial because less electrons, upon relaxation, go toward non-radiative energy transfers. Therefore, it can be concluded that silicon phthalocyanines are good candidates for use as photosensitizers in PDT as they have a higher propensity to fluoresce and generate singlet oxygen. To further support this claim, the molar extinction coeffiecent was calculated for all derivatives. It was found that all derivatives had molar extinction coefficients between 200,000 and $260,000 \mathrm{M}^{-1} \mathrm{~cm}^{-1}$ with methanol as the solvent. These values are in good agreement with the value found for zinc phthalocyanine $(\varepsilon=281,800)$ when dissolved in pyridine.[39] Unfortunately, zinc phthalocyanine is only soluble in pyridine so an exact comparison between the standard and the silicon phthalocyanine derivatives could not be made.

Being non-aggregated compounds, new SiPc derivatives can be modified by "click" reactions with appropriate small molecules, polymers, nano or microparticles, or proteins (cf. Figure 7). An example of such a system is presented in Figure 8, where the photoluminescence spectra of $67 \mathrm{~nm}$ poly(propargyl acrylate) 
(PA) particles, which have been surface modified with $\mathbf{4 a , b}(\mathrm{PA} / \mathrm{SiPcs})$ through copper(I)-catalyzed azide alkyne cycloaddition (CuAAC), is presented. Clearly, the attachment of the fluorophores to the particles have not significantly altered their spectral profile since both exhibit an emission peak at ca. $680 \mathrm{~nm}$.

Previously studied, similar, axially disubstituted PEGylated SiPcs have been shown to be potent photosensitizers and have consistent photocytotoxicity[11, 13, 21]. The properties of these new phthalocyanines $(\mathbf{4 a}, \mathbf{b}$ and $\mathbf{5 a}, \mathbf{b})$ are good candidates for photodynamic therapy (PDT) and the PA/SiPcs assemblies are currently being investigated as phototsentizers with an enhanced permeability and retention (EPR) effect.

\subsubsection{Electrochemical Measurements}

Voltammograms were analyzed in order to derive onset potential $\left(\mathrm{E}_{\text {onset }}\right)$, half-wave potentials $\left(\mathrm{E}_{(1 / 2)}\right)$, peak to peak potential separation for reversible processes $\left(\Delta \mathrm{E}_{p}(\mathrm{mV})\right)$ and peak separation between the first oxidation and first reduction $\left(\mathrm{E}_{\text {gap }}\right)$. The results are presented in Table 3. The voltammograms exhibit one irreversible one electron transfer oxidation process that has an $\mathrm{E}_{\text {onset }}$ of $0.95 \mathrm{~V}$ for the short chain alkyne derivatized $\operatorname{SiPc}(\mathbf{5 a})$. Two reversible reductions are visible with the first $\mathrm{E}_{(1 / 2)}$ occurring at $0.61 \mathrm{~V}$ and the second at 1.06 V. Similarly, the azide derivatized SiPcs (4a and $4 \mathbf{b}$ ) and the PEG 600 alkyne SiPc derivative (5b) exhibit an irreversible one electron oxidative process with similar onset potentials (cf. Table 3 and two reversible reductions. All the redox activity occurring in $\mathbf{4 a}, \mathbf{4} \mathbf{b}, \mathbf{5} \mathbf{a}$, and $\mathbf{5} \mathbf{b}$ is attributed to the phthalocyanine ring due to the central silicon atom being redox inactive.

The prediction of LUMO energies through a CV route can often be quite poor due to the difficulty in assigning the voltage for the oxidation process due to its irreversibility; therefore, Table 3 also presents LUMO $\left(\mathrm{LUMO}_{o p}\right)$ energies based on the difference of CV-derived HOMO values and the energy at the experimentally observed electronic absorption band edge. Clearly, there is a good agreement between the $\mathrm{CV}$ and optically derived bandgaps, where the difference between these values is no greater than $0.11 \mathrm{eV}$ for all the compounds. 


\section{Conclusion}

New axially disubstituted, non-aggregated silicon phthalocyanines (SiPcs), containing azide or alkyne groups have been synthesized and characterized. All obtained SiPcs are highly soluble in common polar, organic solvents with the PEGylated derivatives $(\mathbf{4 b}$ and $\mathbf{5 b}$ ) being soluble in water and other physiologically relevant buffers. The presence of azide and alkyne functional groups in dye molecules, and their high fluorescence and solubility in various solvents make these new compounds useful as a versatile building block in "click" reactions, allowing for the synthesis of a broad spectrum of new compounds for use in biomedical imaging and cancer therapies. The synthetic pathway presented in this paper can be applicable for the synthesis of a variety new axially disubstituted SiPc derivatives with alkyne or azide groups.

\section{Acknowledgments}

The authors thank the Gregg-Graniteville Foundation and the National Science Foundation (DMR-1507266) for financial support.

\section{References Cited}

[1] C. C. Leznoff and Eds. Lever, A. B. P. Phthalocyanines: Properties and applications. 1-3, 1989, 1993, 1996.

[2] N. B. McKeown. Phthalocyanine materials: Synthesis and press, structure and function. 1998.

[3] C. M. Allen, W. M. Sharman, and J. E. Van Lier. Current status of phthalocyanines in the photodynamic therapy of cancer. Journal of Porphyrins and Phthalocyanines, 5(2):161-169, 2001.

[4] T. J. Dougherty, C. J. Gomer, B. W. Henderson, G. Jori, D. Kessel, M. Korbelik, J. Moan, and Q. Peng. Photodynamic therapy. Journal of the National Cancer Institute, 90(12):889-905, 1998.

[5] Dejgj Dolmans, D. Fukumura, and R. K. Jain. Photodynamic therapy for cancer. Nature Reviews Cancer, 3(5):380-387, 2003. 
[6] Michael R. Detty, Scott L. Gibson, and Stephen J. Wagner. Current clinical and preclinical photosensitizers for use in photodynamic therapy. Journal of Medicinal Chemistry, 47(16):3897-3915, 2004.

[7] S. Cassel, C. Debaig, T. Benvegnu, P. Chaimbault, M. Lafosse, D. Plusquellec, and P. Rollin. Original synthesis of linear, branched and cyclic oligoglycerol standards. European Journal of Organic Chemistry, (5):875-896, 2001.

[8] Yunus Zorlu, Mahmut Ali Ermeydan, Fabienne Dumoulin, Vefa Ahsen, Huguette Savoie, and Ross W. Boyle. Glycerol and galactose substituted zinc phthalocyanines. synthesis and photodynamic activity. Photochemical \&3 Photobiological Sciences, 8(3):312-318, 2009.

[9] W. S. Chan, N. Brasseur, C. LaMadeleine, R. Ouellet, and J. E. vanLier. Efficacy and mechanism of aluminium phthalocyanine and its sulphonated derivatives mediated photodynamic therapy on murine tumours. European Journal of Cancer, 33(11):1855-1859, 1997.

[10] N. Brasseur, R. Ouellet, C. La Madeleine, and J. E. van Lier. Water-soluble aluminium phthalocyaninepolymer conjugates for pdt: photodynamic activities and pharmacokinetics in tumour-bearing mice. British Journal of Cancer, 80(10):1533-1541, 1999.

[11] Jan-Willem Hofman, Femke Van Zeeland, Selcan Turker, Herre Talsma, Saskia A. G. Lambrechts, Dmitri V. Sakharov, Wim E. Hennink, and Cornelus F. Van Nostrum. Peripheral and axial substitution of phthalocyanines with solketal groups: Synthesis and in vitro evaluation for photodynamic therapy. J. Med. Chem., 50(7):1485-1494, 2007.

[12] Pui-Chi Lo, Crystal M. H. Chan, Jian-Yong Liu, Wing-Ping Fong, and Dennis K. P. Ng. Highly photo-cytotoxic glucosylated silicon(iv) phthalocyanines. effects of peripheral chloro substitution on the photophysical and photodynamic properties. J. Med. Chem., 50(9):2100-2107, 2007.

[13] Pui-Chi Lo, Shuangqing Wang, Andre Zeug, Matthias Meyer, Beate Roder, and Dennis K. P. Ng. Preparation and photophysical properties of halogenated silicon(iv) phthalocyanines substituted axially with poly(ethylene glycol) chains. Tetrahedron Lett., 44(9):1967-1970, 2003. 
[14] Xiao-Min Shen, Bi-Yuan Zheng, Xiu-Rong Huang, Lei Wang, and Jian-Dong Huang. The first silicon(iv) phthalocyanine-nucleoside conjugates with high photodynamic activity. Dalton Trans., 42(29):1039810403, 2013.

[15] T. Koyama, T. Suzuki, K. Hanabusa, H. Shirai, and N. Kobayashi. A comparison of the loop-current effect of silicon phthalocyanine and silicon naphthalocyanine rings on their axial ligands. Inorganica Chimica Acta, 218(1-2):41-45, 1994.

[16] M. Brewis, G. J. Clarkson, V. Goddard, M. Helliwell, A. M. Holder, and N. B. McKeown. Silicon phthalocyanines with axial dendritic substituents. Angewandte Chemie-International Edition, 37(8):1092-1094, 1998.

[17] Zekeriya Biyiklioglu. Water-soluble axially disubstituted non-aggregated silicon phthalocyanines and their electrochemical properties. Dyes Pigm., 99(1):59-66, 2013.

[18] Luis Martn-Gomisa, Eva M. Barea, Fernando Fernndez-Lzaroa, Juan Bisquert, and ngela Sastre-Santos. Dye sensitized solar cells using non-aggregated silicon phthalocyanines. Journal of Porphyrins and Phthalocyanines, 15(09n10):1004-1010, 2011.

[19] Ayse Aktas and Zekeriya Biyiklioglu. Synthesis and electrochemistry of non-aggregated silicon phthalocyanines bearing unsaturated functional groups. J. Organomet. Chem., 749:364-369, 2014.

[20] Carl A. Barker, Karen S. Findlay, Sylvia Bettington, Andrei S. Batsanov, Igor F. Perepichka, Martin R. Bryce, and Andrew Beeby. Synthesis of new axially-disubstituted silicon-phthalocyanine derivatives: optical and structural characterisation. Tetrahedron, 62(40):9433-9439, 2006.

[21] J. D. Huang, S. Q. Wang, P. C. Lo, W. P. Fong, W. H. Ko, and D. K. P. Ng. Halogenated silicon(iv) phthalocyanines with axial poly(ethylene glycol) chains. synthesis, spectroscopic properties, complexation with bovine serum albumin and in vitro photodynamic activities. New Journal of Chemistry, 28(3):348-354, 2004.

[22] John E. Moses and Adam D. Moorhouse. The growing applications of click chemistry. Chemical Society Reviews, 36(8):1249-1262, 2007. 
[23] Mahmut Ali Ermeydan, Fabienne Dumoulin, Tamara V. Basova, Denis Bouchu, Ayse Gul Gurek, Vefa Ahsen, and Dominique Lafont. Amphiphilic carbohydrate-phthalocyanine conjugates obtained by glycosylation or by azide-alkyne click reaction. New Journal of Chemistry, 34(6):1153-1162, 2010.

[24] Stphane Campidelli, Beatriz Ballesteros, Arianna Filoramo, David Daz Daz, Gema de la Torre, Toms Torres, G. M. Aminur Rahman, Christian Ehli, Daniel Kiessling, Fabian Werner, Vito Sgobba, Dirk M. Guldi, Carla Cioffi, Maurizio Prato, and Jean-Philippe Bourgoin. Facile decoration of functionalized single-wall carbon nanotubes with phthalocyanines via click chemistry. Journal of the American Chemical Society, 130(34):11503-11509, 2008.

[25] Veronika Novakova, Kamil Kopecky, Miroslav Miletin, Jana Ivincova, and Petr Zimcik. Photodynamically active phthalocyanine building blocks for click chemistry. Journal of Porphyrins and Phthalocyanines, 15(09n10):1062-1069, 2011.

[26] Andre Wichmann, Gnter Schnurpfeil, Jana Backenkhler, Lena Kolke, Vladimir A. Azov, Dieter Whrle, Marcus Bumer, and Arne Wittstock. A versatile synthetic strategy for nanoporous goldorganic hybrid materials for electrochemistry and photocatalysis. Tetrahedron, 70(36):6127-6133, 2014.

[27] Xiaochun Chen, Jayan Thomas, Palash Gangopadhyay, Robert A. Norwood, N. Peyghambarian, and Dominic V. McGrath. Modification of symmetrically substituted phthalocyanines using click chemistry: Phthalocyanine nanostructures by nanoimprint lithography. Journal of the American Chemical Society, 131(38):13840-13843, 2009.

[28] Adedayo Fashina, Edith Amuhaya, and Tebello Nyokong. Photophysical studies of newly derivatized mono substituted phthalocyanines grafted onto silica nanoparticles via click chemistry. Spectrochimica Acta Part A: Molecular and Biomolecular Spectroscopy, 140(0):256-264, 2015.

[29] Michal Jurek, Paul H. J. Kouwer, Juraj Rehk, Joseph Sly, and Alan E. Rowan. A novel modular approach to triazole-functionalized phthalocyanines using click chemistry. The Journal of Organic Chemistry, $74(1): 21-25,2009$. 
[30] Zeliha Kanat and Hatice Dincer. The synthesis and characterization of nonperipherally tetra terminal alkynyl substituted phthalocyanines and glycoconjugation via the click reaction. Dalton Transactions, 43(23):8654-8663, 2014.

[31] M. X. Li, E. Khoshdel, and D. M. Haddleton. Synthesis of water soluble pegylated (copper) phthalocyanines via mitsunobu reaction and cu(i)-catalysed azide-alkyne cycloaddition (cuaac) "click" chemistry. Polymer Chemistry, 4(16):4405-4411, 2013.

[32] F. Javier Cespedes-Guirao, Luis Martin-Gomis, Kei Ohkubo, Shunichi Fukuzumi, Fernando Fernandez-Lazaro, and Angela Sastre-Santos. Synthesis and photophysics of silicon phthalocyanineperylenebisimide triads connected through rigid and flexible bridges. Chem. - Eur. J., 17(33):9153-9163, S9153/1-S9153/6, 2011.

[33] Handbook of porphyrin science with applications to chemistry, physics, materials science, engineering, biology and medicine, vol 16: Synthetic developments, pt i. Handbook of Porphyrin Science with Applications to Chemistry, Physics, Materials Science, Engineering, Biology and Medicine, Vol 16: Synthetic Developments, Pt I, 16:1-416, 2012.

[34] K. M. Kadish, K. M. Smith, and R. Guilard. Handbook of porphyrin science with applications to chemistry, physics, materials science, engineering, biology and medicine volume 17 synthetic developments part ii preface for volumes 16-20. Handbook of Porphyrin Science with Applications to Chemistry, Physics, Materials Science, Engineering, Biology and Medicine, Vol 17: Synthetic Developments, Pt Ii, 17:Ix-Ix, 2012.

[35] Zekeriya Biyiklioglu and Huseyin Bas. Synthesis and electrochemistry of non-aggregated axially disubstituted silicon phthalocyanines bearing benzoxazin substituents. Inorganica Chimica Acta, 427:293-298, 2015.

[36] G. L. Lu, S. Lam, and K. Burgess. An iterative route to "decorated" ethylene glycol-based linkers. Chemical Communications, (15):1652-1654, 2006. 
[37] Frank Wuerthner, Theo E. Kaiser, and Chantu R. Saha-Moeller. J-aggregates: From serendipitous discovery to supramolecular engineering of functional dye materials. Angewandte Chemie-International Edition, 50(15):3376-3410, 2011.

[38] P. S. Vincett, E. M. Voigt, and Rieckhof.Ke. Phosphorescence and fluorescence of phthalocyanines. Journal of Chemical Physics, 55(8):4131, 1971.

[39] H. Du, R. C. A. Fuh, J. Z. Li, L. A. Corkan, and J. S. Lindsey. Photochemcad: A computer-aided design and research tool in photochemistry. Photochemistry and Photobiology, 68(2):141-142, 1998. 


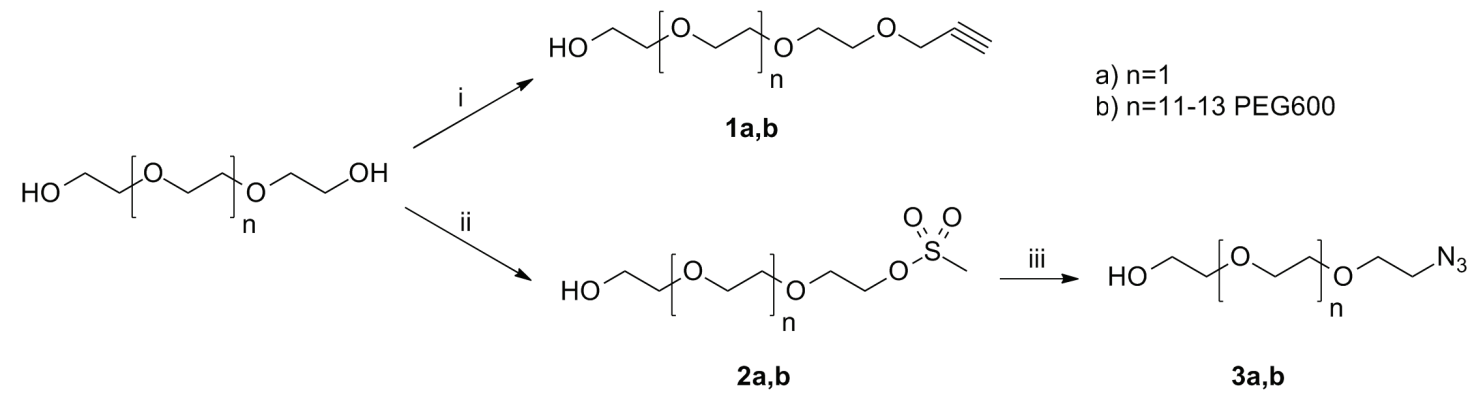

Figure 1: Synthetic route to compounds $\mathbf{1 a}, \mathbf{b}, \mathbf{2 a}, \mathbf{b}$, and $\mathbf{3 a}, \mathbf{b}$; (i) Propargyl bromide, NaH, THF, r.t.; (ii) $\mathrm{MeSO}_{2} \mathrm{Cl}_{1} \mathrm{Et}_{3} \mathrm{~N}$, $\mathrm{CH}_{2} \mathrm{Cl}_{2}$, r.t.; (iii) $\mathrm{NaN}_{3}, \mathrm{~m}$ acetonitrile, reflux.

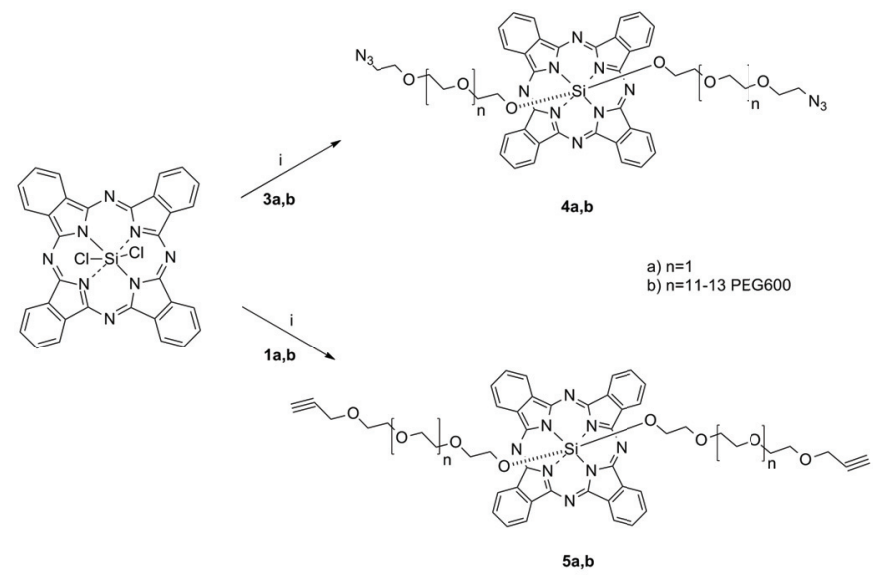

Figure 2: Synthetic route to compounds $\mathbf{4 a}, \mathbf{b}$ and $\mathbf{5 a}, \mathbf{b}$; (i) Reaction conditions: NaH, toluene, reflux. 


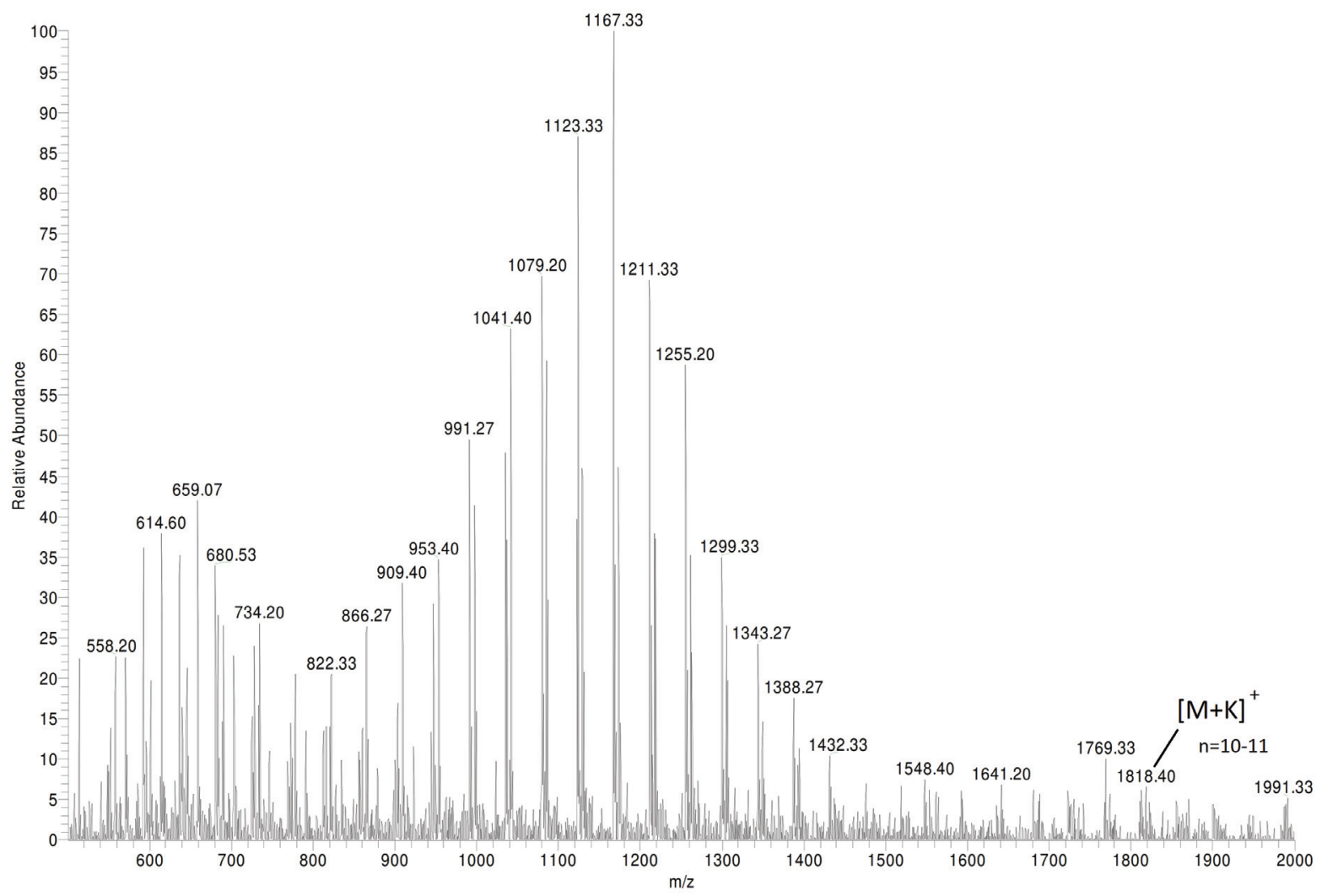

Figure 3: ESI Mass analysis of $\mathbf{5 b}$, positive ionization.

\begin{tabular}{ccc}
\hline \hline compound & $\lambda_{a b s}(\mathrm{~nm})$ & $\lambda_{\text {em }}(\mathrm{nm})$ \\
\hline $4 \mathrm{a}$ & $352,606,671$ & 683 \\
$4 \mathrm{~b}$ & $358,607,676$ & 680 \\
$5 \mathrm{a}$ & $354,604,672$ & 681 \\
$5 \mathrm{~b}$ & $355,604,672$ & 680 \\
\hline
\end{tabular}

Table 1: Absorption and emission of $\mathbf{4 a}, \mathbf{b}$ and $\mathbf{5 a}, \mathbf{b}$ in methanol at a concentration of $5 \mu \mathrm{g} / \mathrm{mL}$. Excitation at $630 \mathrm{~nm}$.

\begin{tabular}{ccc}
\hline \hline compound & $\varepsilon^{a}\left(\mathrm{M}^{-1} \mathrm{~cm}^{-1}\right)$ & $\phi_{F}^{b}$ \\
\hline $4 \mathrm{a}$ & 259900 & 0.50 \\
$4 \mathrm{~b}$ & 209200 & 0.51 \\
$5 \mathrm{a}$ & 208600 & 0.52 \\
5b & 218500 & 0.51 \\
\hline
\end{tabular}

Table 2: Molar extinction coefficient and fluorescence quantum yield of all four silicon phthalocyanine derivatives. ${ }^{a}$ Solvent is methanol. ${ }^{b}$ Solvent is toluene with $1 \%$ pyridine. Excitation at $665 \mathrm{~nm}$. 


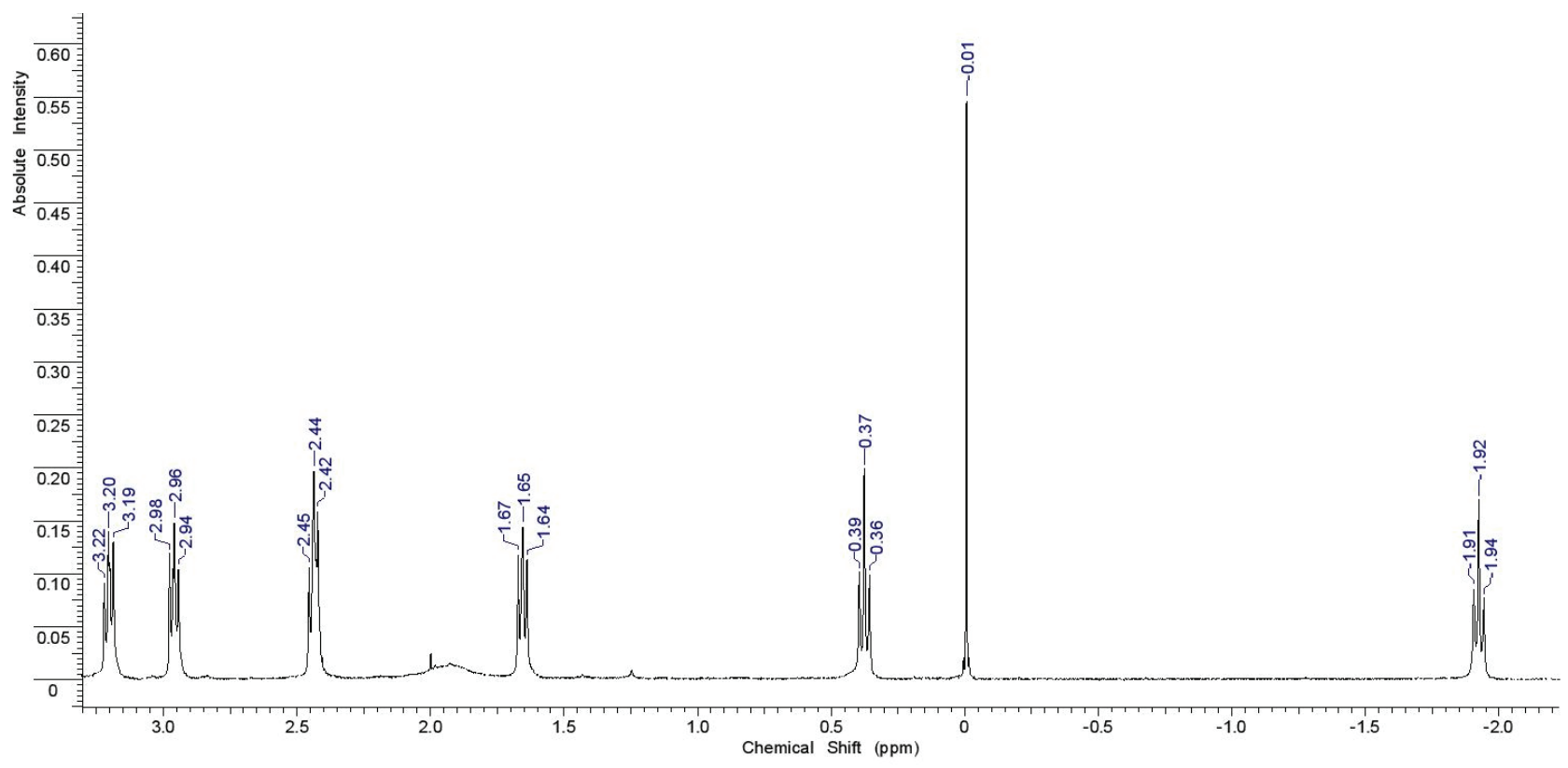

Figure 4: ${ }^{1} \mathrm{H}$ NMR spectrum of $\mathbf{5} \mathbf{b}$ in $\mathrm{CDCl}_{3}$. Methylene groups closest to the SiPc ring have the highest upfield shift.

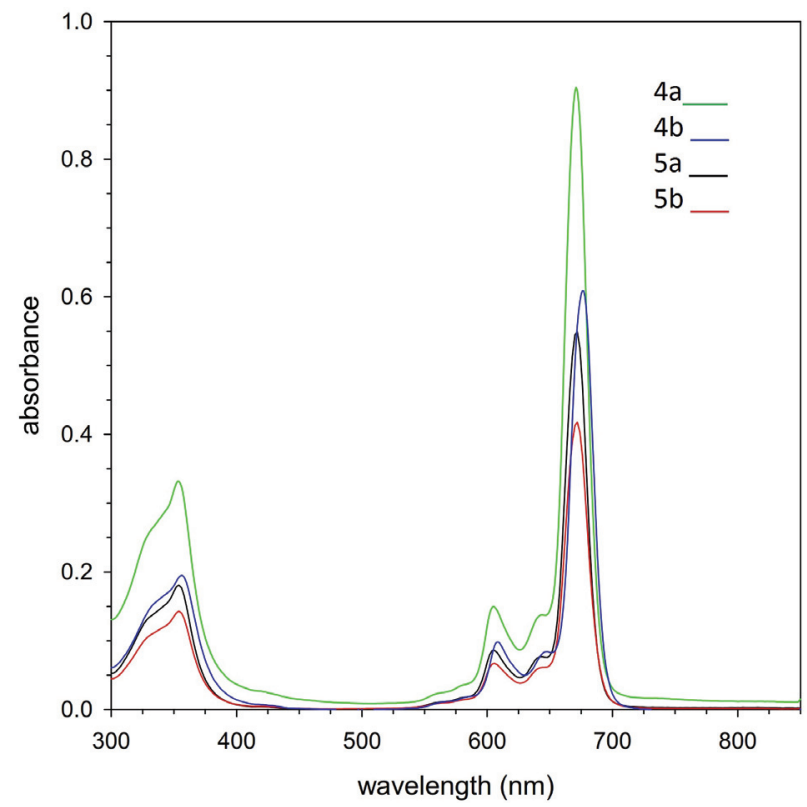

Figure 5: Absorption of $\mathbf{4 a}, \mathbf{b}$ and $\mathbf{5 a}, \mathbf{b}$ in methanol at a concentration of $5 \mu \mathrm{g} / \mathrm{mL}$. 

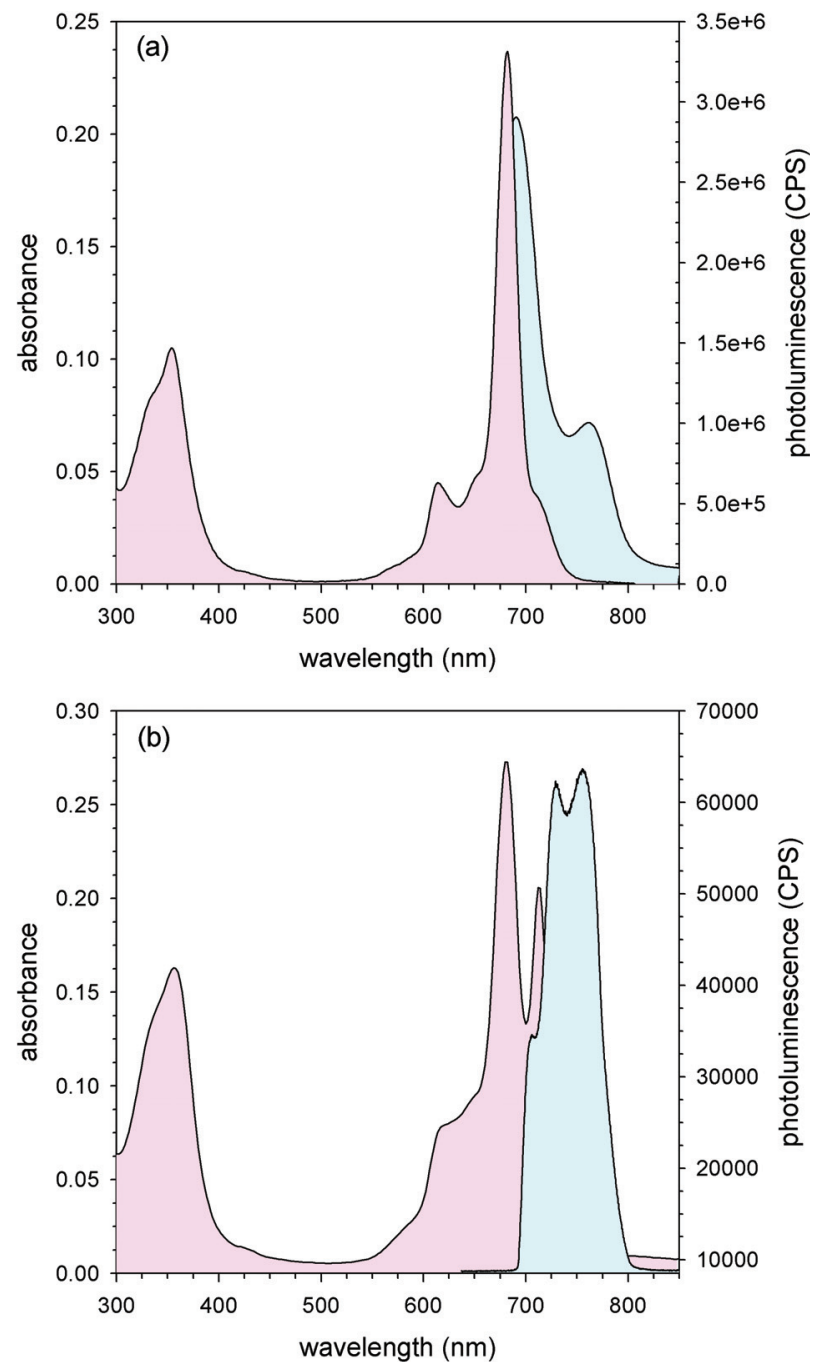

Figure 6: Absorption (pink) and emission (green) of (a) $\mathbf{4 b}$ and (b) $\mathbf{5 b}$ in water at a concentration of $5 \mu \mathrm{g} / \mathrm{mL}$. Excitation at $630 \mathrm{~nm}$.

\begin{tabular}{lcccccc}
\hline \hline compound & $\Delta \mathrm{E}_{o p}^{a}$ & $\mathrm{E}(\mathrm{V})^{b}$ & $\mathrm{HOMO}^{c}$ & $\mathrm{LUMO}^{d}$ & $\Delta \mathrm{E}^{e}$ & $\mathrm{LUMO}_{o p}^{f}$ \\
\hline $4 \mathrm{a}$ & 1.653 & 0.948 & 5.348 & & 1.544 & \\
& & -0.592 & & 3.808 & & 3.695 \\
\hline $4 \mathrm{~b}$ & 1.653 & 0.948 & 5.348 & & 1.540 & \\
& & -0.596 & & 3.804 & & 3.695 \\
\hline $5 \mathrm{a}$ & 1.653 & 0.948 & 5.368 & & 1.570 & \\
& & -0.606 & & 3.794 & & 3.695 \\
\hline $5 \mathrm{~b}$ & 1.653 & 0.948 & 5.348 & & 1.554 & \\
& & -0.606 & & 3.794 & & 3.695 \\
\hline
\end{tabular}

Table 3: Electronic characteristics of SiPc compounds measured through cyclic voltammetery and UV-vis spectroscopy; all energies are relative to the vacuum level. ${ }^{a}$ optical bandgap taken from electronic absorption band edge ${ }^{b} \mathrm{E}_{1} / 2$ for reduction $\left(E_{p a}+E_{p c}\right) / 2$ vs. $\mathrm{Ag} / \mathrm{AgCl}$ at $100 \mathrm{mV} \mathrm{s}^{-1}$. Oxidation was irreversible, onset potential utilized ${ }^{c} \mathrm{E}_{H O M O}=-E_{R 1} 1_{(1 / 2)}-4.4$ ${ }^{d} \mathrm{E}_{L U M O}=-E_{O 1_{\text {(onset) }}}-4.4^{e} \Delta \mathrm{E}=\mathrm{E}_{L U M O}-\mathrm{E}_{H O M O}{ }^{f}$ value based on difference of CV-derived HOMO energy and energy at experimentally observed electronic absorption band edge 


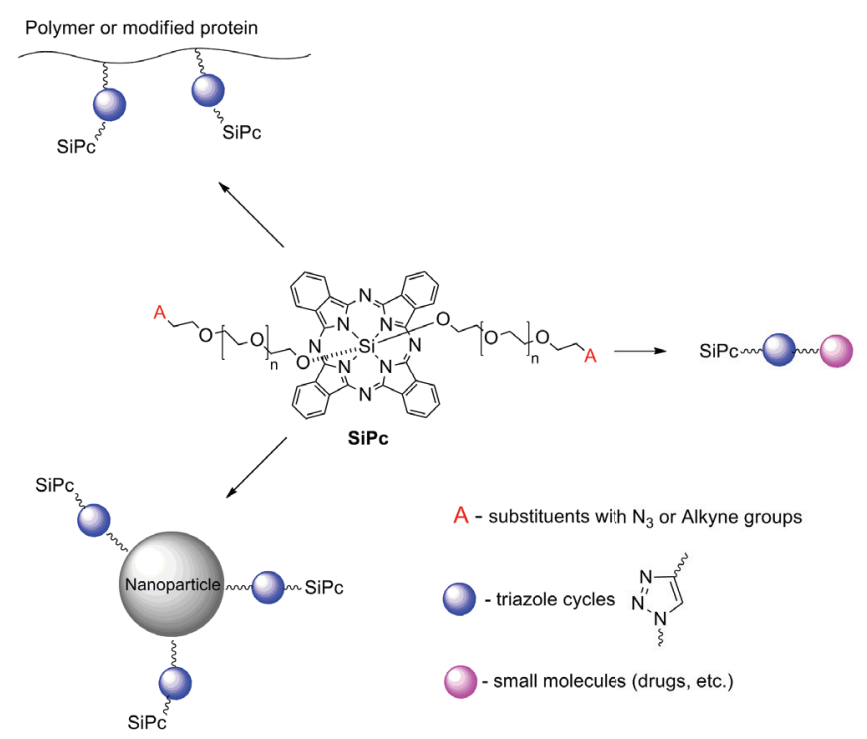

Figure 7: Possible routes, which employ $\operatorname{SiPcs}(\mathbf{4 a}, \mathbf{b}$ and $\mathbf{5 a}, \mathbf{b})$, to construct complex systems via "click" reactions. See Figure 8 for a specific example.

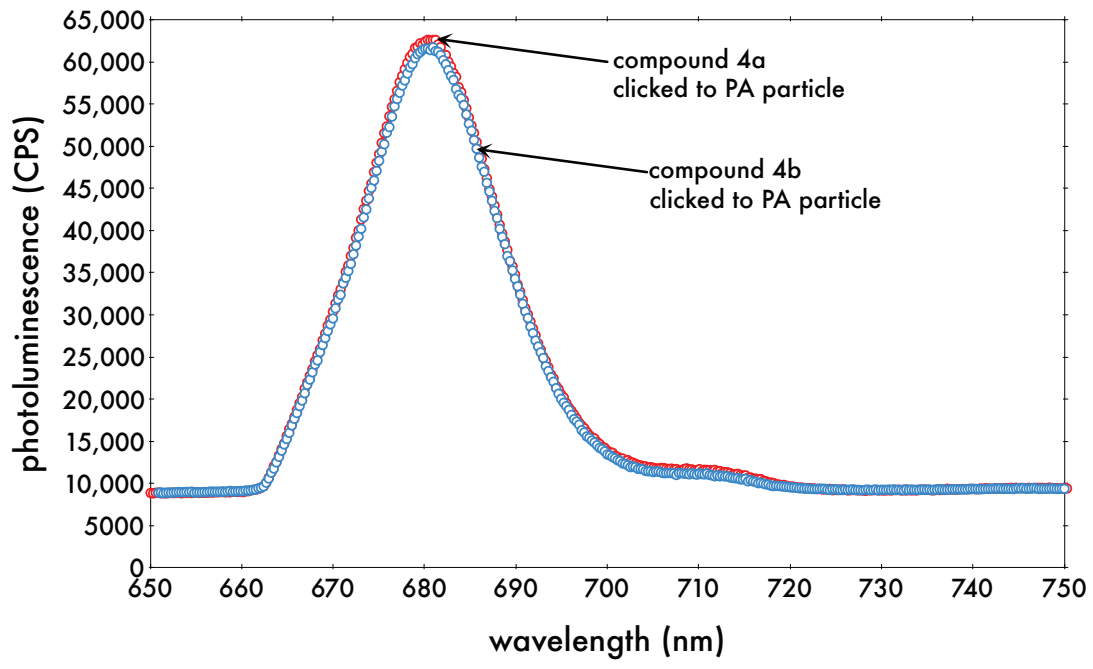

Figure 8: Photoluminescence spectra of $67 \mathrm{~nm}$ poly(propargyl acrylate) (PA) particles surface modified with 4a,b through copper(I)-catalyzed azide alkyne cycloaddition (CuAAC). Particles dispersed in DMSO. Excitation wavelength was $630 \mathrm{~nm}$. 


\section{List of Figures}

1 Synthetic route to compounds 1a, $\mathbf{b}, \mathbf{2 a}, \mathbf{b}$, and $\mathbf{3 a}, \mathbf{b}$; (i) Propargyl bromide, NaH, THF, r.t.; (ii) $\mathrm{MeSO}_{2} \mathrm{Cl}$,

$\mathrm{Et}_{3} \mathrm{~N}, \mathrm{CH}_{2} \mathrm{Cl}_{2}$, r.t.; (iii) $\mathrm{NaN}_{3}$, m acetonitrile, reflux. . . . . . . . . . . . . . . . . . . . . 18

2 Synthetic route to compounds $\mathbf{4} \mathbf{a}, \mathbf{b}$ and $\mathbf{5 a , b}$; (i) Reaction conditions: NaH, toluene, reflux. . . . . . . . 18

3 ESI Mass analysis of $\mathbf{5 b}$, positive ionization. . . . . . . . . . . . . . . . . . . . . 19

$4 \quad{ }^{1} \mathrm{H}$ NMR spectrum of $\mathbf{5} \mathbf{b}$ in $\mathrm{CDCl}_{3}$. Methylene groups closest to the SiPc ring have the highest upfield shift. 20

$5 \quad$ Absorption of $\mathbf{4 a}, \mathbf{b}$ and $\mathbf{5 a}, \mathbf{b}$ in methanol at a concentration of $5 \mu \mathrm{g} / \mathrm{mL}$. . . . . . . . . . . . . . 20

6 Absorption (pink) and emission (green) of (a) $\mathbf{4 b}$ and (b) $\mathbf{5 b}$ in water at a concentration of $5 \mu \mathrm{g} / \mathrm{mL}$.

Excitation at $630 \mathrm{~nm} . \ldots \ldots \ldots \ldots$. . . . . . . . . . . . . . . . . . . . 21

$7 \quad$ Possible routes, which employ $\operatorname{SiPcs}(\mathbf{4 a}, \mathbf{b}$ and $\mathbf{5 a}, \mathbf{b})$, to construct complex systems via "click" reactions.

See Figure 8 for a specific example. . . . . . . . . . . . . . . . . . . . . . . . . . . . . . . . . . . . 22

8 Photoluminescence spectra of $67 \mathrm{~nm}$ poly(propargyl acrylate) (PA) particles surface modified with $4 \mathbf{4 a , b}$ through copper(I)-catalyzed azide alkyne cycloaddition (CuAAC). Particles dispersed in DMSO. Excitation wavelength was $630 \mathrm{~nm} . \ldots \ldots \ldots$

\section{List of Tables}

1 Absorption and emission of $\mathbf{4 a}, \mathbf{b}$ and $\mathbf{5 a}, \mathbf{b}$ in methanol at a concentration of $5 \mu \mathrm{g} / \mathrm{mL}$. Excitation at $630 \mathrm{~nm}$.

2 Molar extinction coefficient and fluorescence quantum yield of all four silicon phthalocyanine derivatives. ${ }^{a}$ Solvent is methanol. ${ }^{b}$ Solvent is toluene with $1 \%$ pyridine. Excitation at $665 \mathrm{~nm} . \quad$. . . . . . . . . . . 19 Electronic characteristics of SiPc compounds measured through cyclic voltammetery and UV-vis spectroscopy; all energies are relative to the vacuum level. ${ }^{a}$ optical bandgap taken from electronic absorption band edge ${ }^{b} \mathrm{E}_{1} / 2$ for reduction $\left(E_{p a}+E_{p c}\right) / 2$ vs. $\mathrm{Ag} / \mathrm{AgCl}$ at $100 \mathrm{mV} \mathrm{s}^{-1}$. Oxidation was irreversible, onset potential utilized ${ }^{c} \mathrm{E}_{H O M O}=-E_{R 1_{(1 / 2)}}-4.4{ }^{d} \mathrm{E}_{L U M O}=-E_{O 1_{(o n s e t)}}-4.4{ }^{e} \Delta \mathrm{E}=\mathrm{E}_{L U M O}-\mathrm{E}_{H O M O}{ }^{f}$ value based on difference of CV-derived HOMO energy and energy at experimentally observed electronic absorption band

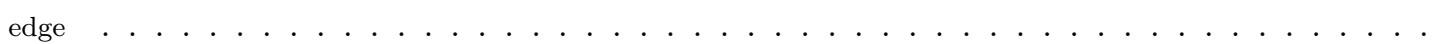

